\title{
Template-Assisted Synthesis of Ruthenium Oxide Nanoneedles: Electrical and Electrochemical Properties
}

Mahima Subhramannia, Beena K. Balan, Bhaskar R. Sathe, Imtiaz S. Mulla and

Vijayamohanan K. Pillai*

\section{Electronic Supplementary Information (ESI)}

Figure ESI-1

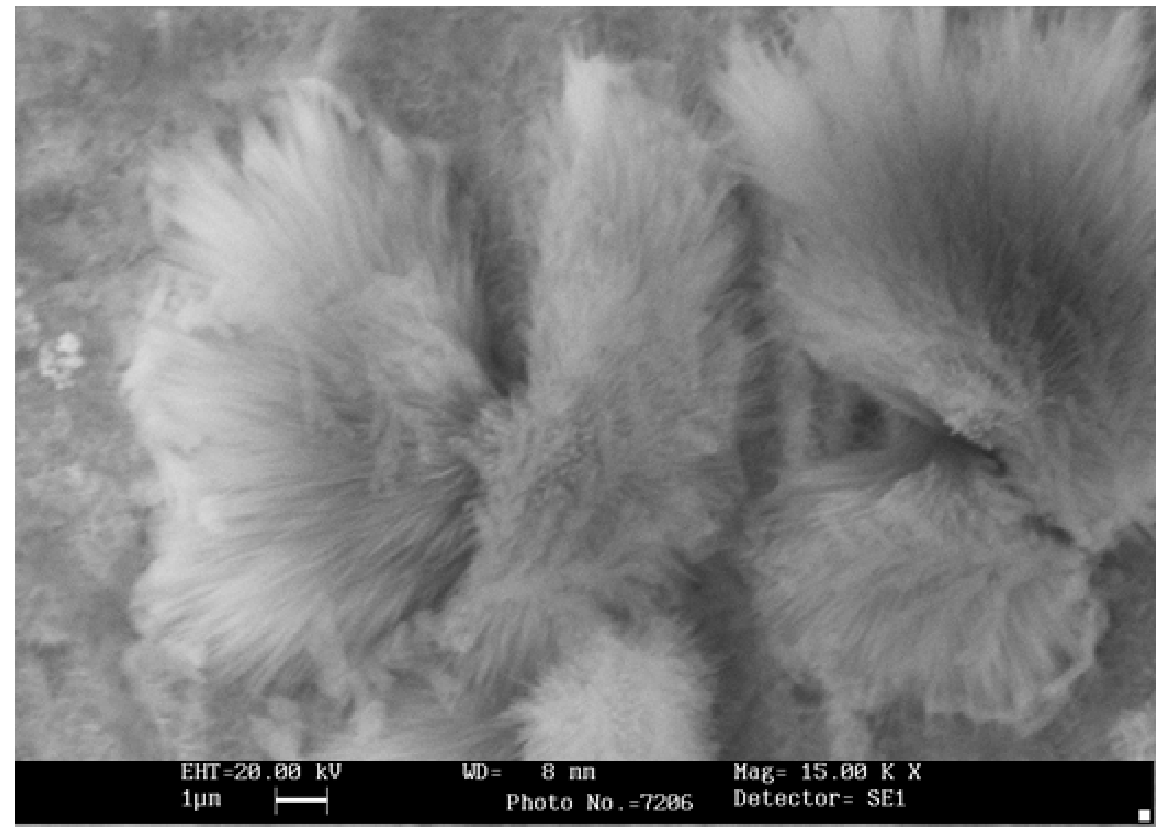

Figure ESI-1 shows the scanning electron micrographs of $\mathrm{RuO}_{2}$ nanoneedles after etching the alumina membrane (image taken for a different sample) 
Figure ESI-2

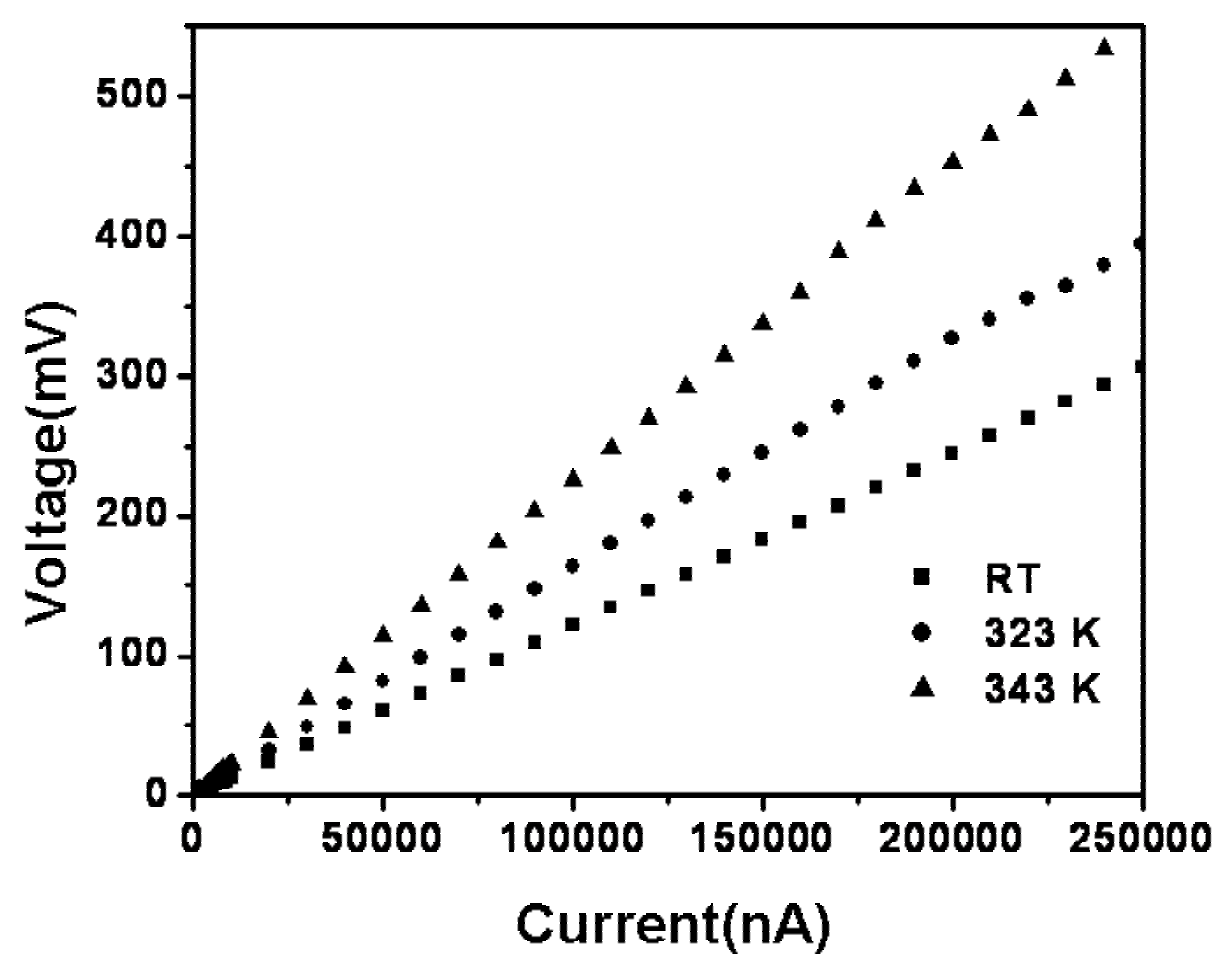

Figure ESI-2 shows the $\mathrm{I}-\mathrm{V}$ response of $\mathrm{RuO}_{2}$ nanoneedles measured using a fourpoint probe method. The plot shows linear I-V curves at different temperatures exhibiting ohmic contact throughout the measurements. 


\section{Figure ESI-3}
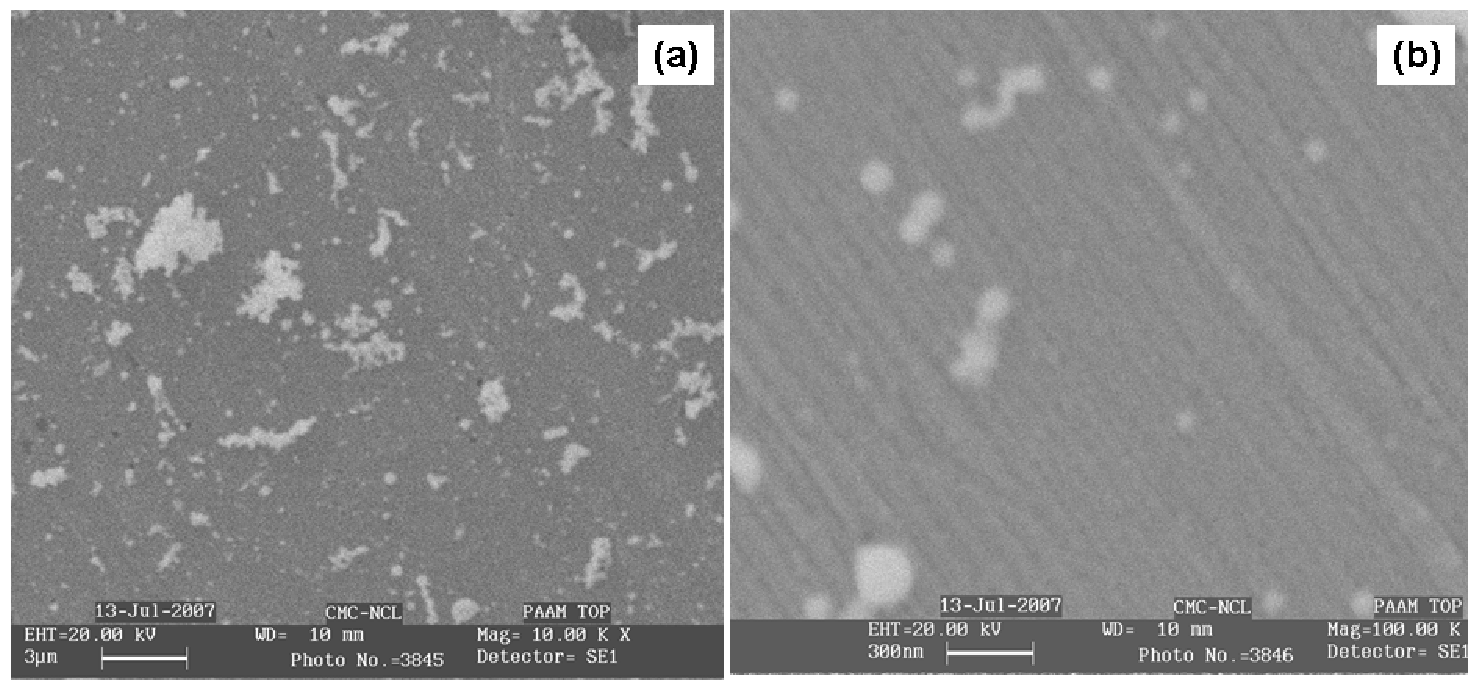

Figure ESI-3 shows the $\mathrm{RuO}_{2}$ incorporated PAAM (a) top view and (b) crosssectional view. 